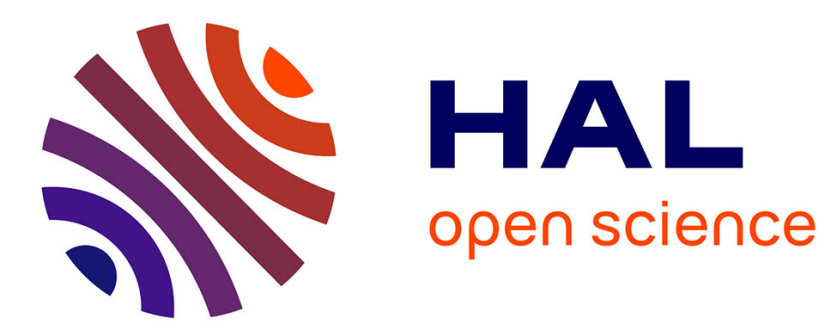

\title{
Three-Dimensional Constitutive Model Considering Transformation-Induced Damage and Resulting Fatigue Failure in Shape Memory Alloys
}

Darren Hartl, Yves Chemisky, Fodil Meraghni

\section{- To cite this version:}

Darren Hartl, Yves Chemisky, Fodil Meraghni. Three-Dimensional Constitutive Model Considering Transformation-Induced Damage and Resulting Fatigue Failure in Shape Memory Alloys. SPIE, Behavior and Mechanics of Multifunctional Materials and Composites, Mar 2014, San Diego, California, United States. 10.1117/12.2046668 . hal-01199560

\section{HAL Id: hal-01199560 \\ https://hal.science/hal-01199560}

Submitted on 15 Sep 2015

HAL is a multi-disciplinary open access archive for the deposit and dissemination of scientific research documents, whether they are published or not. The documents may come from teaching and research institutions in France or abroad, or from public or private research centers.
L'archive ouverte pluridisciplinaire HAL, est destinée au dépôt et à la diffusion de documents scientifiques de niveau recherche, publiés ou non, émanant des établissements d'enseignement et de recherche français ou étrangers, des laboratoires publics ou privés. 


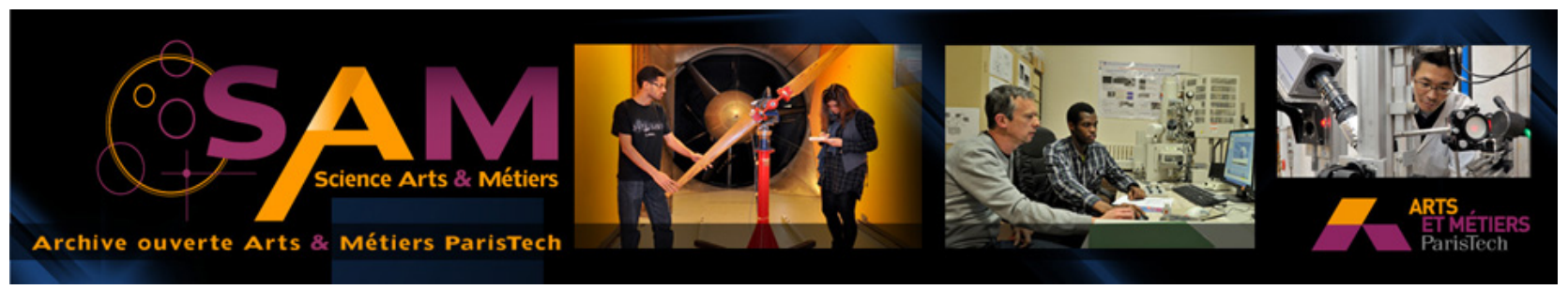

\section{Science Arts \& Métiers (SAM)}

is an open access repository that collects the work of Arts et Métiers ParisTech researchers and makes it freely available over the web where possible.

This is an author-deposited version published in: http://sam.ensam.eu

Handle ID: .http://hdl.handle.net/10985/10012

\section{To cite this version :}

Darren HARTL, Yves CHEMISKY, Fodil MERAGHNI - Three-Dimensional Constitutive Model Considering Transformation-Induced Damage and Resulting Fatigue Failure in Shape Memory Alloys - 2014 


\title{
Three-Dimensional Constitutive Model Considering Transformation-Induced Damage and Resulting Fatigue Failure in Shape Memory Alloys
}

\author{
Darren J. Hartl ${ }^{*} a$, Yves Chemisky ${ }^{b}$, Fodil Meraghni ${ }^{b}$ \\ ${ }^{a}$ Department of Aerospace Engineering, Texas A\&M University, College Station, TX USA \\ ${ }^{b}$ Arts et Mtiers ParisTech, LEM3 CNRS, Metz, France
}

\begin{abstract}
In this work, a constitutive model is developed that describe the behavior of shape memory alloys undergoing a large number of cycles, developing internal damage, and eventually failing. Physical mechanisms associated with martensitic phase transformation occurring during cyclic loadings such as transformation strain generation and recovery, transformation-induced plasticity, and fatigue damage are all taken into account within a thermodynamically consistent framework. Fatigue damage is described utilizing a continuum theory of damage. The damage growth rate has been formulated as a function of both the stress state and also the magnitude of the transformation strain, while the complete or partial nature of the transformation cycles is also considered as per experimental observations. Simulation results from the model developed are compared to uniaxial actuation fatigue tests at different stress levels. It is shown that both lifetime and the evolution irrecoverable strain can be accurately simulated.
\end{abstract}

\section{INTRODUCTION}

Shape memory alloys are metals that have the ability to undergo and recover substantial deformation during a thermomechanical cycle. The physical mechanism that drives the shape recovery is a martensitic phase transformation that takes place in SMAs during thermal and/or mechanical loadings, without the appareance of significant plastic strain during the formation of martensitic plates. This unique ability has led to the development of devices for aerospace and medial applications. The design of such structures has required the development of constitutive models to be able to predict their thermomechanical behavior. A comprehensive review of SMA constitutive models can be found in works by ${ }^{1234}$. All these models describe the behavior of conventional SMAs and, since the operating temperatures and maximum stress levels are relatively low, no influence of irrecoverable strains due to creep or high stress effects have been taken into account. The evolution of transformation induced plasticity has been further considered for conventional SMAs by ${ }^{5}$ and $^{6}$ to account for the appearance of irrecoverable strains upon cycling. The coupling between phase transformation and plasticity has been considered in the literature for the simulation of shape memory alloys that operates a low temperatures (compared to their melting temperatures), but where the stress level can reach the plastic yield stress ${ }^{789}$. A model that account for the effect of retained martensite (martensite pinned by dislocations) has been developed by. ${ }^{10}$ To predict the influence of irrecoverable strains of high-temperature SMAs (HTSMAs), a one dimensional model accounting for the coupling between phase transformation and viscoplasticity has been recently developed by $^{11}$ for the simulation of HTSMAs, where viscoplastic creep is observed. A three-dimensional extension of this model was developed and implemented in a FEA software by ${ }^{12}$, and the cyclic evolution of irrecoverable strains accounting for combined viscoplastic, retained martensite and TRIP effect was further implemented by ${ }^{13}$. The development of such models were primarily designed to account for the development of irrecoverable strains during the training step to stabilize the SMA behavior. But thermomechanical cycling induces thermally-induced fatigue in SMAs ${ }^{1415}$. During the lifetime of an SMA actuator, the influence of fatigue on the performances of the actuator is twofold: Structural fatigue describes the failure of components, while functional fatigue is the part related to the development of irrecoverable strain. The prediction of structural fatigue is necessary to be able to determine the lifetime of an actuator while the prediction of functional fatigue is necessary to determine

Send correspondence to D. J. Hartl e-mail: darren.hartl@tamu.edu 
the evolution of the structural response of an actuator over its lifetime. In this work, a three-dimensionnal model for fatigue failure of SMAs including the appearance of irrecoverable strains is developed within a thermodynamic framework. A continuum theory of damage $\mathrm{e}^{161718}$ is utilized to describe the evolution of structural fatigue damage, while the evolution of transformation induced plasticity describe the functional fatigue.

\section{MOTIVATING CONSIDERATIONS}

Extensive experimental study of actuation fatigue and post-mortem analyses were carried out on Ni60Ti40 (wt. \%). ${ }^{19}$ It has been shown that a significant amount of cracks were present in the SMA at failure, as shown in Fig. 1. This indicates that a progressive damage mechanism is activated during the lifetime of the alloy. The Continuum Theory of Damage (CDM) is particularly adapted for such fatigue damage, according to its continuous and progressive evolution of number of defects. Also, this study suggests that failure may not be due to plastic strain, as regularly considered in ductile metals. Indeed, the amount of irrecoverable strains is not correlated with the lifetime of the samples, as shown in Fig. 2 b). On the other hand, this study has shown that the number of cycles before failure is increasing while the actuation works decreases (see Fig. 2 a) ). This motivates the choice of a thermodynamical model to describe the evolution of damage in shape memory alloys.
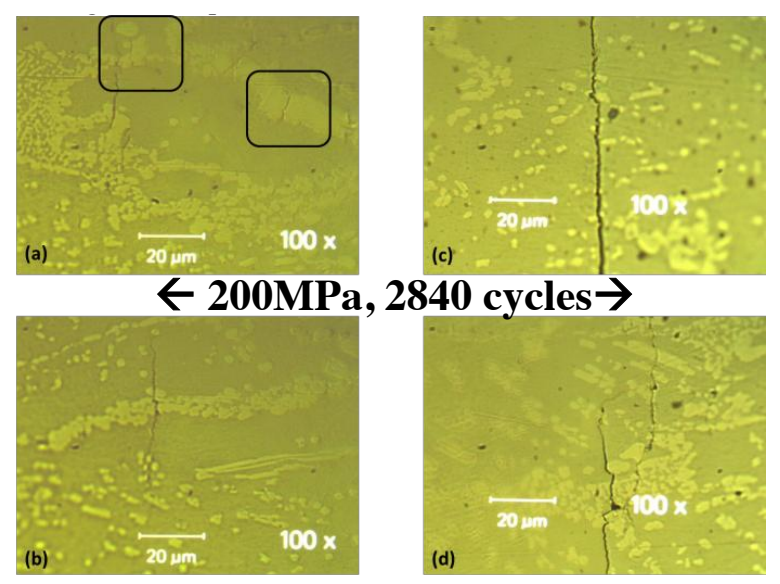

Figure 1. Examples of damage in nickel-rich NiTi material. Note the micro cracks initiating within precipitates, resulting in relative small observable strains but eventually leading to specimen failure ${ }^{19}$

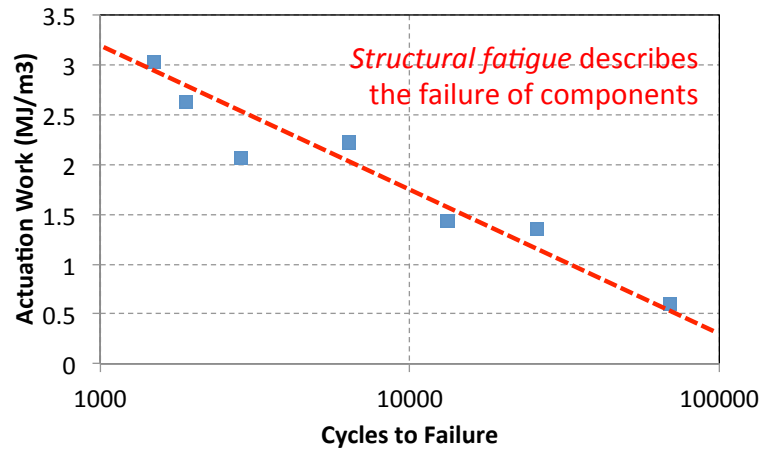

(a) Strong correlation between actuation work and cycles to failure

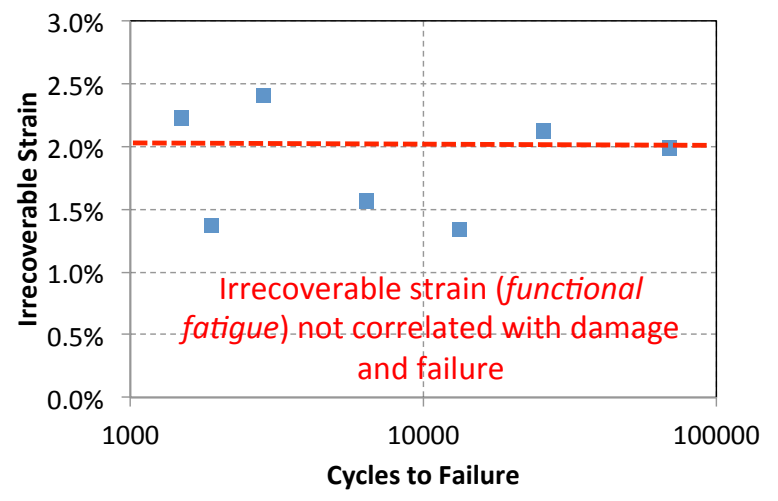

(b) No correlation between total strain at failure and fatigue life

Figure 2. Decoupling of observed irrecoverable strain and cycles to failure, which seems more strongly related to actuation work per cycle ${ }^{19}$ 


\section{CONSTITUTIVE MODELING FRAMEWORK FOR PHASE TRANSFORMATION AND DAMAGE}

Shape Memory Alloys structural and functional failure happens at relatively small strain, therefore the proposed constitutive model for the description of the behavior for SMAs under a large number of actuation cycles is formulated in the framework of infinitesimal strains. The inelastic strain mechanisms are tracked using the following internal variables:

- The inelastic transformation strain $\varepsilon^{t}$. Actually the inelastic transformation strain describe the evolution of inelastic strain associated to different physical phenomena as long as they appear during transformation. The inelastic transformation strain is therefore a contribution of transformation, plasticity and damage.

- The scalar total martensitic volume fraction $\xi$,

- The scalar transformation hardening energy $g^{t}$,

- The scalar accumulative plasticity accompanying martensitic transformation

- The scalar plastic hardening energy $g^{t p}$

- The scalar (i.e., isotropic) damage accumulation $D$

A Gibbs free energy $\mathrm{G}$ defined as an additive decomposition into a thermoelastic contribution $G^{A}$ from local regions in the austenitic phase, a thermoelastic contribution $G^{M}$ from local regions in the martensitic phase, and a mixing term $G^{i n}$ that accounts for the change in the Gibbs free energy due to non thermoelastic processes. According to the state variables chosen for the description of the thermomechanical mechanisms, the Gibbs energy for the overall SMA material is written:

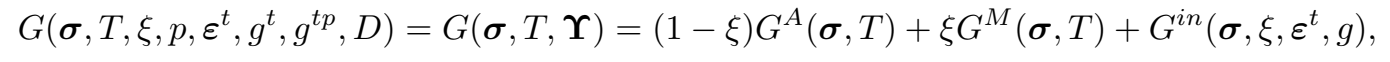

Following the framework of classical plasticity as extended to transformation per, ${ }^{20}$ we propose the existence of an elastic domain in the seven-dimensional $\sigma-T$ hyperspace. Martensitic transformation happens either from austenite to martensite (forward transformation) or from martensite to austenite (reverse transformation). A transformation limit surface shall be defined in the $\boldsymbol{\sigma}-T$ hyperspace for each condition (forward and reverse). The elastic domain is therefore defined as the intersection of two convex domains that bounded by a surface that represent the critical value to trigger forward and reverse transformation, respectively.

The two domains functions that defines the forward and reverse transformation limits are expressed as:

$$
\begin{gathered}
\Phi^{f w d}(\boldsymbol{\Gamma})=\Phi\left(\Gamma_{\boldsymbol{\varepsilon}^{t}}, \Gamma_{\xi}, \Gamma_{g^{t}}, \Gamma_{p}, \Gamma_{g^{t p}} \Gamma_{D}\right) \\
\Phi^{r e v}(\boldsymbol{\Gamma})=\Phi\left(\Gamma_{\boldsymbol{\varepsilon}^{t}}, \Gamma_{\xi}, \Gamma_{g^{t}}, \Gamma_{p}, \Gamma_{g^{t p}} \Gamma_{D}\right)
\end{gathered}
$$

The contribution of the transformation hardening is considered as a linear function of the volume fraction of martensite. This particular form has been chosen since the interaction energy between martensite variants increases with martensitic volume fration. The transformation hardening $g^{t}$ The contribution of the plastic hardening is considering as a linear function of the accumulative plastic strain

Following the Coleman-Noll procedure ${ }^{2122}$ identically in the manner described in detail elsewhere ${ }^{2324}$ and assuming that all internal variables evolve simultaneously as a result of a single underlying physical process (i.e., martensitic phase transformation either forward or reverse), the rates of change of the internal state variables are determined in a thermodynamically consistent manner:

$$
\dot{\boldsymbol{\varepsilon}}^{t}=\lambda \frac{\partial \Phi}{\partial \boldsymbol{\Gamma}_{\boldsymbol{\varepsilon}^{t}}}, \quad \dot{\xi}=\lambda \frac{\partial \Phi}{\partial \Gamma_{\xi}}, \quad \dot{g^{t}}=\lambda \frac{\partial \Phi}{\partial \Gamma_{g^{t}}}, \quad \dot{p}=\lambda \frac{\partial \Phi}{\partial \Gamma_{p}}, \quad g^{t p}=\lambda \frac{\partial \Phi}{\partial \Gamma_{g^{t p}}}, \quad \dot{D}=\lambda \frac{\partial \Phi}{\partial \Gamma_{D}} .
$$


A particular form is chosen for the forward and reverse transformation (recall that the stress is the conjugate variable of the transformation strain):

$$
\begin{aligned}
\Phi^{f w d}(\boldsymbol{\Gamma}) & =\hat{\Phi}^{f w d}(\boldsymbol{\sigma})\left(f^{t}(\xi)+f^{t p}(p)\right)+\Gamma_{\xi} f^{t}(\xi)+\Gamma_{p} f^{t p}(p) \\
& +\Gamma_{D} f^{D}\left(\hat{\Phi}^{f w d}(\boldsymbol{\sigma})\right)+H^{t}(\xi)+H^{t p}(p)-\pi_{c} \\
\Phi^{r e v}(\boldsymbol{\Gamma}) & =\hat{\Phi}^{r e v}\left(\boldsymbol{\sigma}, \Gamma^{m}\right)\left(f^{t}(\xi)+f^{t p}(p)\right)+\Gamma_{\xi} f^{t}(\xi)+\Gamma_{p} f^{t p}(p) \\
& +\Gamma_{D} f^{D}\left(\hat{\Phi}^{r e v}\left(\boldsymbol{\sigma}, \Gamma^{m}\right)\right)+H^{t}(\xi)+H^{t p}(p)+\pi_{c}
\end{aligned}
$$

which lead to the following definition of the internal variables (since $\dot{\xi}=\lambda$ )

$$
\dot{\varepsilon}^{t}=\left(f^{t}+f^{t p}+\Gamma_{D} \frac{\mathrm{d} f^{D}}{\mathrm{~d} \hat{\Phi}}+\right) \frac{\mathrm{d} \hat{\Phi}}{\mathrm{d} \boldsymbol{\xi}} \dot{\xi}, \quad \dot{g}^{t}=\frac{\mathrm{d} H^{t}}{\mathrm{~d} \xi} \quad \dot{p}=\lambda f^{t p} \dot{\xi} \quad \dot{g}^{t p}=\left(\frac{\mathrm{d} H^{t p}}{\mathrm{~d} p}+\Gamma_{p} \frac{\mathrm{d} f^{t p}}{\mathrm{~d} p}\right) \quad \dot{D}=\lambda f^{D}(\hat{\Phi}) \dot{\xi}
$$

The transformation strain direction tensor is defined as, following ${ }^{24}$

$$
\frac{\mathrm{d} \hat{\Phi}}{\mathrm{d} \boldsymbol{\sigma}}=\boldsymbol{\Lambda}^{t r}=\left\{\begin{array}{ll}
\frac{3}{2} H^{c u r}(\bar{\sigma}) \frac{\boldsymbol{\sigma}^{\prime}}{\bar{\sigma}} ; & \mathrm{d} \xi \geq 0 \text { and } 0 \leq \xi<1 \\
\frac{\boldsymbol{\varepsilon}^{t-r}}{\xi^{r}} ; & \mathrm{d} \xi \leq 0 \text { and } 0<\xi \leq 1
\end{array},\right.
$$

where

$$
H^{c u r}(\bar{\sigma})= \begin{cases}H_{\min } & ; \quad \bar{\sigma} \leq \bar{\sigma}_{\text {crit }}, \\ H_{\min }+\left(H_{\max }-H_{\min }\right)\left(1-e^{-k\left(\bar{\sigma}-\bar{\sigma}_{\text {crit }}\right)}\right) & ; \quad \bar{\sigma}>\bar{\sigma}_{\text {crit }} .\end{cases}
$$

The transformation function $f^{t}$ has been set to 1 following such definition of the transformation strain direction tensor, while the transformation induced plasticity direction function $f^{t p}$ is set as

The definition of the transformation plasticity magnitude function $f^{t p}(\xi)$ follows the work of ${ }^{6}$ and ${ }^{13}$ and is taken to be

$$
f^{t p}(p)=\frac{C_{1}^{p}}{H_{\max }} e^{\frac{-p}{C_{2}^{p}}} \operatorname{sgn}(\mathrm{d} \xi)
$$

where

$$
\zeta=\int_{t_{0}}^{t} \frac{H_{c u r}(\bar{\sigma})}{H_{\max }}|\dot{\xi}|
$$

Finally, the damage accumulation function $f^{D}(\hat{\Phi})$ is taken to be

$$
\frac{\mathrm{d} D}{D_{\text {crit }}}=\frac{\mathrm{d} N}{N_{f}} \Rightarrow \frac{\dot{D}}{D_{\text {crit }}}=\frac{\dot{N}}{N_{f}}
$$

Considering that we consider fatigue occurring only as a consequence transformation cycles (full or partial), and that a full cycle corresponds in the evolution of the martensitic volume fraction from 0 to 1 and back to 0 , this is rewritten as

$$
\dot{D}=|\dot{\xi}| \frac{D_{\text {crit }}}{2 N_{f}}=\dot{\xi} \frac{D_{\text {crit }}}{2 N_{f}} \operatorname{sgn}(\mathrm{d} \xi)=\dot{\xi} f^{D} .
$$

To determine a form for the function $f^{D}$, a practical solution for is to link the evolution of damage with the number of cycles to failure $N_{f} .{ }^{25}$ A power-law is defined as a function of the transformation function $\hat{\Phi}(\boldsymbol{\sigma})$.

$$
N_{f}=\left(\frac{\hat{\Phi}}{C^{d}}\right)^{-\gamma_{d}}
$$




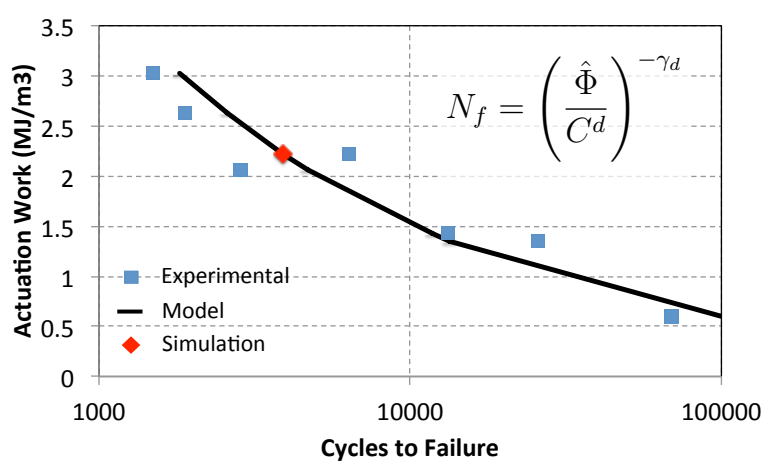

(a)

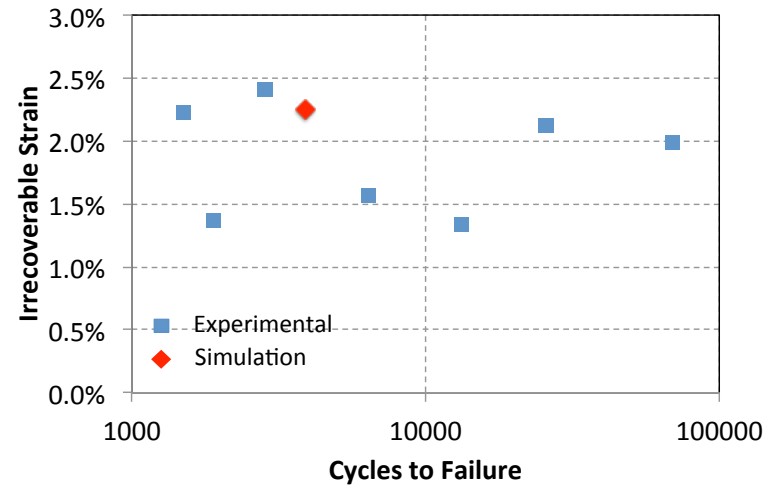

(b)

Figure 3. Effectiveness of the power law of (3.13) in fitting the experimental fatigue data associated with some material systems $^{19}\left(C^{d}=62.3, \gamma_{d}=2.48\right)$. Irrecoverable strains simulated by the model at failure (3900 cycles)

This form has been motivated by the clear relationship established between the number of cycles at failure and the actuation work per cycle ${ }^{19}$ as previously illustrated in Fig. 2a). Fig. 3a) shows how the effectiveness of the functional form of (3.13) in fitting the failure data associated with the material of Fig. 1 and Fig. $2 .{ }^{19}$ Figure 3b) shows the amount of irrecoverable strain (i.e. TRIP strain) predicted by the model considering the

Combining (3.12) and (3.13), the damage accumulation function writes:

$$
f^{D}(\hat{\Phi})=\frac{D_{\text {crit }}}{2}\left(\frac{\hat{\Phi}}{C^{d}}\right)^{\gamma_{d}} \operatorname{sgn}(\mathrm{d} \xi) .
$$

The entire three-dimensional constitutive model for shape memory alloys experiencing cycling fatigue can then be summarized as follows: given a loading history in terms of $\varepsilon$ and $T$, we evolve the transformation strain $\varepsilon^{t}$, the stress $\sigma$, and the total martensitic volume fraction $\xi$ using the stress-strain coupling as described by the constitutive law, the transformation strain evolution equation (3.6), and the constraints on the evolution of the martensitic volume fraction $\xi$ (bounded between 0 and 1 ).

The model has been applied to simulate the behavior of an SMA undergoing three thousand and nine hundred cycles. uniaxial isobaric cycles at a constant stress of $200 \mathrm{Mpa}$, from $500 \mathrm{~K}$ to $200 \mathrm{~K}$. The evolution of the total strain as a function of temperature is presented in Figure 4 for the first fourty cycles. The evolution of the accumulative plastic strain $p$, and the Damage variable $D$ are presented over the three thousand and nine hundred cycles.

\section{CONCLUSION}

A three-dimensional thermodynamical model focused on the description of fatigue of actuators has been developed, based on the concept of continuum damage mechanics. The evolution of damage is describe using a power-law function, following the conclusions of an extensive study of actuation fatigue of a Ni60Ti40 (wt. \%) samples. It is shown that the model is able to accurately simulate the structural and functional fatigue of this shape memory alloy composition. The model is also able to capture the evolution of irrecoverable strains during the lifetime of material, considering that plastic strain is accompanying martensitic transformation. These promising uniaxial results require to be validated using an extensive database to obtain the lifetime as a function of the loading path for actuation, but also other types of loading paths, including superelasticity

\section{ACKNOWLEDGEMENTS}

This work was supported by the NSF International Institute of Materials for Energy Conversion (IIMEC), award \#0844082. 


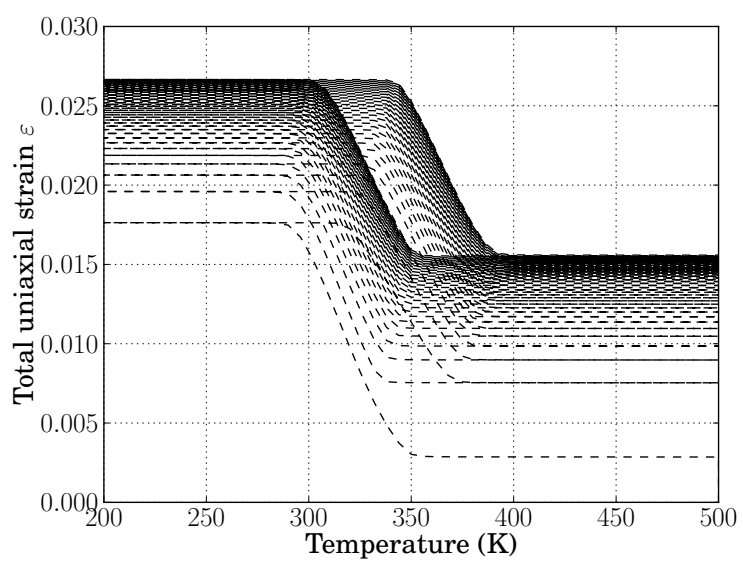

(a)

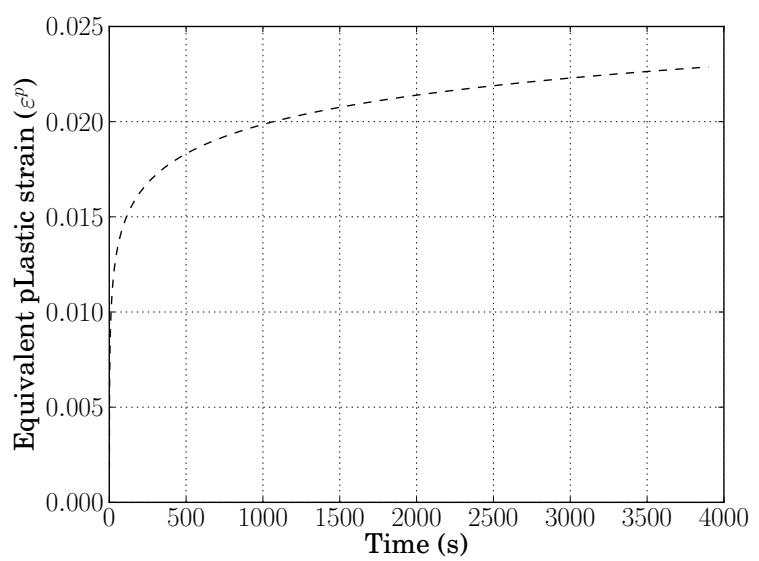

(b)

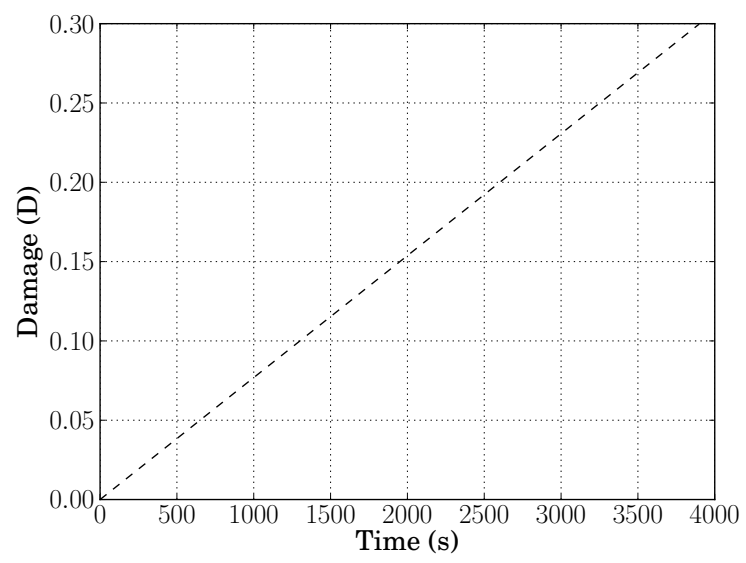

(c)

Figure 4. a) Evolution of total strain during the first twenty-five cycles; b) Evolution of the accumulated plastic strain; c) Evolution of the damage

\section{REFERENCES}

[1] V. Birman, "Review of mechanics of shape memory alloy structures," Applied Mechanics Reviews 50(11), pp. 629-645, 1997.

[2] E. Patoor, D. C. Lagoudas, P. B. Entchev, L. C. Brinson, and X. Gao, "Shape memory alloys, Part I: General properties and modeling of single crystals," Mechanics of Materials 38(5-6), pp. 391-429, 2006.

[3] D. C. Lagoudas, P. B. Entchev, P. Popov, E. Patoor, L. C. Brinson, and X. Gao, "Shape memory alloys, Part II: Modeling of polycrystals," Mechanics of Materials 38(5-6), pp. 430-462, 2006.

[4] A. Paivia and M. Savi, "An overview of constitutive models for shape memory alloys," Mathematical Problems in Engineering 2006, pp. 1-30, 2006.

[5] D. C. Lagoudas and Z. Bo, "Thermomechanical modeling of polycrystalline SMAs under cyclic loading, Part II: Material characterization and experimental results for a stable transformation cycle," International Journal of Engineering Science 37, pp. 1141-1173, 1999.

[6] D. Lagoudas and P. Entchev, "Modeling of transformation-induced plasticity and its effect on the behavior of porous shape memory alloys: Part I: Constitutive model for fully dense SMAs," Mechanics of Materials 36(9), pp. 865-892, 2004. 
[7] D. Hartl and D. Lagoudas, "Constitutive modeling and structural analysis considering simultaneous phase transformation and plastic yield in shape memory alloys," Smart Materials and Structures 18(1-17), 2009.

[8] W. Zaki, S. Zamfir, and Z. Moumni, "An extension of the zm model for shape memory alloys accounting for plastic deformation," Mechanics of Materials 42(3), pp. 266-274, 2010.

[9] W. Khalil, A. Mikolajczak, C. Bouby, and T. B. Zineb, "A constitutive model for fe-based shape memory alloy considering martensitic transformation and plastic sliding coupling: Application to a finite element structural analysis," Journal of Intelligent Material Systems and Structures 23(10), pp. 1143-1160, 2012.

[10] L. Saint-Sulpice, S. A. Chirani, and S. Calloch, "A 3d super-elastic model for shape memory alloys taking into account progressive strain under cyclic loadings," Mechanics of materials 41(1), pp. 12-26, 2009.

[11] D. C. Lagoudas, G. Chatzigeorgiou, and P. K. Kumar, "Modeling and experimental study of simultaneous creep and transformation in polycrystalline high-temperature shape memory alloys," Journal of Intelligent Material Systems and Structures 20(18), pp. 2257-2267, 2009.

[12] D. J. Hartl, G. Chatzigeorgiou, and D. C. Lagoudas, "Three-dimensional modeling and numerical analysis of rate-dependent irrecoverable deformation in shape memory alloys," International Journal of Plasticity 26(10), pp. 1485-1507, 2010.

[13] Y. Chemisky, G. Chatzigeorgiou, P. Kumar, and D. C. Lagoudas, "A constitutive model for cyclic actuation of high-temperature shape memory alloys," Mechanics of Materials 68, pp. 120-136, 2014.

[14] O. W. Bertacchini, D. C. Lagoudas, and E. Patoor, "Thermomechanical transformation fatigue of tinicu sma actuators under a corrosive environment-part i: Experimental results," International Journal of Fatigue 31(10), pp. 1571-1578, 2009.

[15] D. C. Lagoudas, D. A. Miller, L. Rong, and C. Li, "Thermomechanical transformation fatigue of SMA actuators," in Proceedings of SPIE, Smart Structures and Materials, 3992, pp. 420-429, 2000.

[16] J. Hult, "Cdm- capabilities, limitations and promises(continuum damage mechanics)," Mechanisms of deformation and fracture, pp. 233-247, 1979.

[17] J.-L. Chaboche, "Continuous damage mechanics: A tool to describe phenomena before crack initiation," Nuclear Engineering and Design 64(2), pp. 233 - 247, 1981.

[18] D. Krajcinovic, "Continuum damage mechanics," Applied Mechanics Reviews 37, pp. 1-6, 1984.

[19] B. O. Agboola, D. J. Hartl, and D. C. Lagoudas, "A study of actuation fatigue of shape memory alloy," in ASME 2012 Conference on Smart Materials, Adaptive Structures and Intelligent Systems, pp. 287-293, American Society of Mechanical Engineers, 2012.

[20] M. A. Qidwai and D. C. Lagoudas, "On the thermodynamics and transformation surfaces of polycrystalline NiTi shape memory alloy material," International Journal of Plasticity 16, pp. 1309-1343, 2000.

[21] B. D. Coleman and W. Noll, "Material symmetry and thermostatic inequalities in finite elastic deformations," Archive for Rational Mechanics and Analysis 15, pp. 87-111, 1964.

[22] B. D. Coleman and M. E. Gurtin, "Thermodynamics with internal state variables," The Journal of Chemical Physics 47, pp. 597-613, July 1967.

[23] L. Machado and D. Lagoudas, "Thermomechanical constitutive modeling of SMAs," in Shape Memory Alloys: Modeling and Engineering Applications, D. Lagoudas, ed., ch. 3, pp. 122-187, Springer-Verlag, New York, 2008.

[24] D. C. Lagoudas, D. J. Hartl, Y. Chemisky, L. Machado, and P. Popov, "Constitutive model for the numerical analysis of phase transformation in polycrystalline shape memory alloys," International Journal of Plasticity 32-33, pp. 155-183, 2012.

[25] J. Lemaitre and J.-L. Chaboche, Mechanics of Solid Materials, Cambridge University Press, Cambridge, UK, 1990. 


\section{APPENDIX A. MATERIAL PARAMETERS FOR THE NI60TI40 (WT. \%)}

MATERIAL

Table 1. Model parameters for Ni60T40 (wt\%)

\begin{tabular}{cl}
\hline Parameter & Value \\
\hline$E_{A}$ & $70 \mathrm{GPa}$ \\
$E_{M}$ & $70 \mathrm{GPa}$ \\
$\nu^{M}=\nu^{A}$ & 0.33 \\
$\alpha^{M}=\alpha^{A}$ & $0 \mathrm{~K}^{-1}$ \\
$M_{s}$ & $293 \mathrm{~K}$ \\
$M_{f}$ & $273 \mathrm{~K}$ \\
$A_{s}$ & $313 \mathrm{~K}$ \\
$A_{f}$ & $333 \mathrm{~K}$ \\
$C_{A}$ & $7 \mathrm{MPa} / \mathrm{K}$ \\
$C_{M}$ & $7 \mathrm{MPa} / \mathrm{K}$ \\
$n_{1}, n_{2}, n_{3}, n_{4}$ & $0.6,0.6,0.6,0.6$ \\
$H^{c u r}(|\sigma|)$ & 0.0111 \\
$\sigma_{c r i t}$ & $0 \mathrm{MPa}$ \\
$w^{t p}$ & 0.6 \\
$C_{1}^{t p}$ & 0.017 \\
$C_{2}^{t p}$ & 0.2 \\
$R^{t p}$ & -2 \\
$D^{c r i t}$ & 0.3 \\
$\gamma^{D}$ & 2.48 \\
$C^{D}$ & 62.29 \\
\hline
\end{tabular}

